\title{
Morphometric analyses reveal synonymy of two monotypic genera, Huangiella and Tumoris (Acari, Eriophyoidea, Eriophyidae)
}

\author{
Chin-Fah Wang', Chi-Chien Kuo², Ming-Luen Jeng², Kun-Wei Huang ${ }^{2}$ \\ I General Education Center, National Chiayi University, Chiayi 600, Taiwan, R.O.C. 2 Department of Zoo- \\ logy, National Museum of Natural Science, Taichung 404, Taiwan, R.O.C. \\ Corresponding author: Kun-Wei Huang (eri@mail.nmns.edu.tw)
}

Academic editor: Andre Bochkov | Received 25 January 2011 | Accepted 8 April 2011 | Published 2 June 2011

Citation: Wang C-F, Kuo C-C, Jeng M-L, Huang K-W (2011) Morphometric analyses reveal synonymy of two monotypic genera, Huangiella and Tumoris (Acari, Eriophyoidea, Eriophyidae). ZooKeys 102: 1-11. doi: 10.3897/zookeys. 102.948

\begin{abstract}
Morphological variation of Huangiella lanyuensis (Huang, 2001) and Tumoris sanasaii Huang, 2001 from Taiwan was analyzed using multivariate statistical methods. We show that these species are the same and propose to use the name Tumoris sanasaii. No significant differences between populations from Lanyu and Green Island (type localities for H. lanyuensis and T. sanasaii, respectively) were found; however, mites from Yangmingshan (northern Taiwan) differed substantially from these two groups. Synonymy resulted from our study is as follows: Huangiella Kammerer, 2006 is a junior synonym of Tumoris Huang, 2001; Absentia lanyuensis Huang, 2001 is a junior synonym of Tumoris sanasaii Huang, 2001. We also study the sexual variation of populations from Green Island. The result showed the females significantly larger than the males at 17 variables.
\end{abstract}

\section{Keywords}

Multivariate analysis, Eriophyid mites, Lanyu, Green Island, valid name, Tumoris sanasaii

\section{Introduction}

Eriophyid mites, also known as gall, blister, erineum, bud and rust mites, have more than 200 genera and about 3700 described species worldwide (De Lillo and Amrine 2003). They differ from the other mites by having only two pairs of legs and by their entirely herbivorous habits. The body is minute in size $(80-250 \mu \mathrm{m})$ with most of the body structures reduced. These characteristics make them a difficult taxon to study and the actual diversity may be several folds higher than currently known (Amirne 1996).

Copyright Chin-Fah Wang et al. This is an open access article distributed under the terms of the Creative Commons Attribution License, which permits unrestricted use, distribution, and reproduction in any medium, provided the original author and source are credited. 
Huang (2001a, b) established two monotypic eriophyid genera Absentia and Tumoris based on A. lanyuensis Huang and T. sanasaii Huang, respectively. The former species was reported from Symplocos cochinchinensis philippinensis (originally misidentified as S. c. cochinchinensis) in Lanyu (Orchid Island) (Huang 2001a), whereas the latter was collected from Green Island (Ludao) from the same plant subspecies (Huang 2001b). No subsequent species has been added to these two genera since then. The name Absentia was later found preoccupied and a replacement name, Huangiella, was proposed by Kammerer (2006).

Here we add another mite population from S. c. cochinchinensis in northern Taiwan and made several morphometric analyses to determine if these groups are distinct. Sexual variation in the Green Island population was also analyed by multivariate analysis to reveal the morphological difference between sexes.

\section{Materials and methods}

\section{Acquisition of specimens and preparation of slide specimens}

Specimens used in the present study were collected from Lanyu $\left(22^{\circ} 2^{\prime} 45^{\prime \prime} \mathrm{E}\right.$, $\left.121^{\circ} 31^{\prime} 50 " \mathrm{~N}\right)$ in 31-Aug.-1994, 18-Aug.-1998 and 28-May-2008, from Green Island $\left(22^{\circ} 39^{\prime} 52^{\prime \prime} \mathrm{E}, 121^{\circ} 29^{\prime} 17^{\prime \prime} \mathrm{N}\right)$ in 5-Jun.-2000 (collected from different trees), and from Yangmingshan $\left(25^{\circ} 10^{\prime} 15^{\prime \prime} \mathrm{E}, 121^{\circ} 34^{\prime} 26^{\prime \prime} \mathrm{N}\right)$ in 18-Aug.-1999 and 24-Aug.-1999 (prepared and measured by CFW and KWH). Specimen mounting was followed by Huang (2008). Every specimen was mounted dorso-ventrally on a single slide.

Through microscopic examination, 136 out of the 246 slides prepared from the mite samples collected from S. c. philippinensis on Lanyu and Green Island were found to be the species in question. Eighty-five individuals allowing measurements of all morphometric variables, including 32 females from Lanyu (LF), 22 males and 31 females from Green Island (GM and GF, respectively), were chosen for morphometric measurement and analysis. We also prepared mite specimens collected from Symplocos c. cochinchinensis in Yangmingshan (north Taiwan). Out of 24 individuals, 16 females (YF) were chosen for measurements.

\section{Variable Selection and Measurement}

Thirty-three variables for morphometric analyses were selected and measured (Table 1). The variables includes ones based on the the homologous landmarks or length of setae commonly used in taxonomic descriptions. The distance between setal tubercles was measured by truss method (Strauss and Bookstein 1982; Huang et al. 1996) (Fig. 1), and was doubly measured in opposite orientations then averaged. All morphometric data in this study were shown in micrometers $(\mu \mathrm{m})$. 
Table I. 33 morphometric characters and their abbreviation used in this study.

\begin{tabular}{|c|c|c|}
\hline \multicolumn{2}{|c|}{ Variables } & \multirow{2}{*}{$\begin{array}{l}\text { Abbreviation } \\
\mathrm{BL} \\
\end{array}$} \\
\hline 1 & body length & \\
\hline 2 & shield length & SL \\
\hline 3 & shield width & SW \\
\hline 4 & distance between the dorsal tubercles & Dt-Dt \\
\hline 5 & dorsal setae length & Ds.l \\
\hline 6 & distance between the 1 st coxal tubercles & $\mathrm{Ct} 1-\mathrm{Ct} 1$ \\
\hline 7 & 1st coxal setae length & Ct1.1 \\
\hline 8 & distance between the 2nd coxal tubercles & $\mathrm{Ct} 2-\mathrm{Ct} 2$ \\
\hline 9 & the 2 nd coxal setae length & Ct2.1 \\
\hline 10 & distance between the 3 rd coxal tubercles & $\mathrm{Ct} 3-\mathrm{Ct} 3$ \\
\hline 11 & the 3rd coxal setae length & Ct3.1 \\
\hline 12 & cross distance from the 1 st to the 2 nd coxal tubercles & $\mathrm{Ct} 1 \backslash \mathrm{Ct} 2$ \\
\hline 13 & distance from the 1 st to the 2 nd coxal tubercles & $\mathrm{Ct} 1-\mathrm{Ct} 2$ \\
\hline 14 & cross distance from the 2 nd to the 3 rd coxal tubercles & $\mathrm{Ct} 2 \mathrm{lCt} 3$ \\
\hline 15 & distance from the 2 nd to the 3 rd coxal tubercles & $\mathrm{Ct} 2-\mathrm{Ct} 3$ \\
\hline 16 & genital width & Gs.W \\
\hline 17 & genital length & Gs.L \\
\hline 18 & distance between the genital tubercles & Gt-Gt \\
\hline 19 & genital setae length & Gs.l \\
\hline 20 & distance between the lateral tubercles & Lt-Lt \\
\hline 21 & lateral setae length & Lt.l \\
\hline 22 & cross distance from the lateral tubercles to the 1 st ventral tubercles & Lt|Vt1 \\
\hline 23 & distance from the lateral tubercles to the 1 st ventral tubercles & Lt-Vt1 \\
\hline 24 & distance between the 1 st ventral tubercles & $\mathrm{Vt} 1-\mathrm{Vt1}$ \\
\hline 25 & the 1st ventral setae length & Vt1.1 \\
\hline 26 & distance between the 3rd ventral tubercles & $\mathrm{Vt} 3-\mathrm{Vt} 3$ \\
\hline 27 & the 3rd ventral setae length & Vt3.1 \\
\hline 28 & cross distance from the 3rd coxal tubercles to the genital tubercles & $\mathrm{Ct} 3 \backslash \mathrm{Gt}$ \\
\hline 29 & distance from the 3rd coxal tubercles to the genital tubercles & Ct3-Gt \\
\hline 30 & cross distance from the genital tubercles to the lateral tubercles & Gt $\mid \mathrm{Lt}$ \\
\hline 31 & distance from the genital tubercles to the lateral tubercles & Gt-Lt \\
\hline 32 & cross distance from the genital tubercles to the 1 st ventral tubercles & Gt $\mid V t 1$ \\
\hline 33 & distance from the genital tubercles to the 1 st ventral tubercles & Gt-Vt1 \\
\hline
\end{tabular}

\section{Analysis}

We evaluated geographic and sexual variations in morphology with multivariate analysis of variance (MANOVA). Morphometric data obtained from 101 mites from three localities was analyzed. Females of Yangmingshan, females of Lanyu, and females of Green Island $(\mathrm{YF}+\mathrm{LF}+\mathrm{GF})$ were used to test if they are the same species, whereas the individuals from Green Island (GM and GF) were used to detect the sexual variation. Morphometric measurements (including distance between setal bases and the lengths of setae) were standardized by subtracted the mean. Principal components analysis 

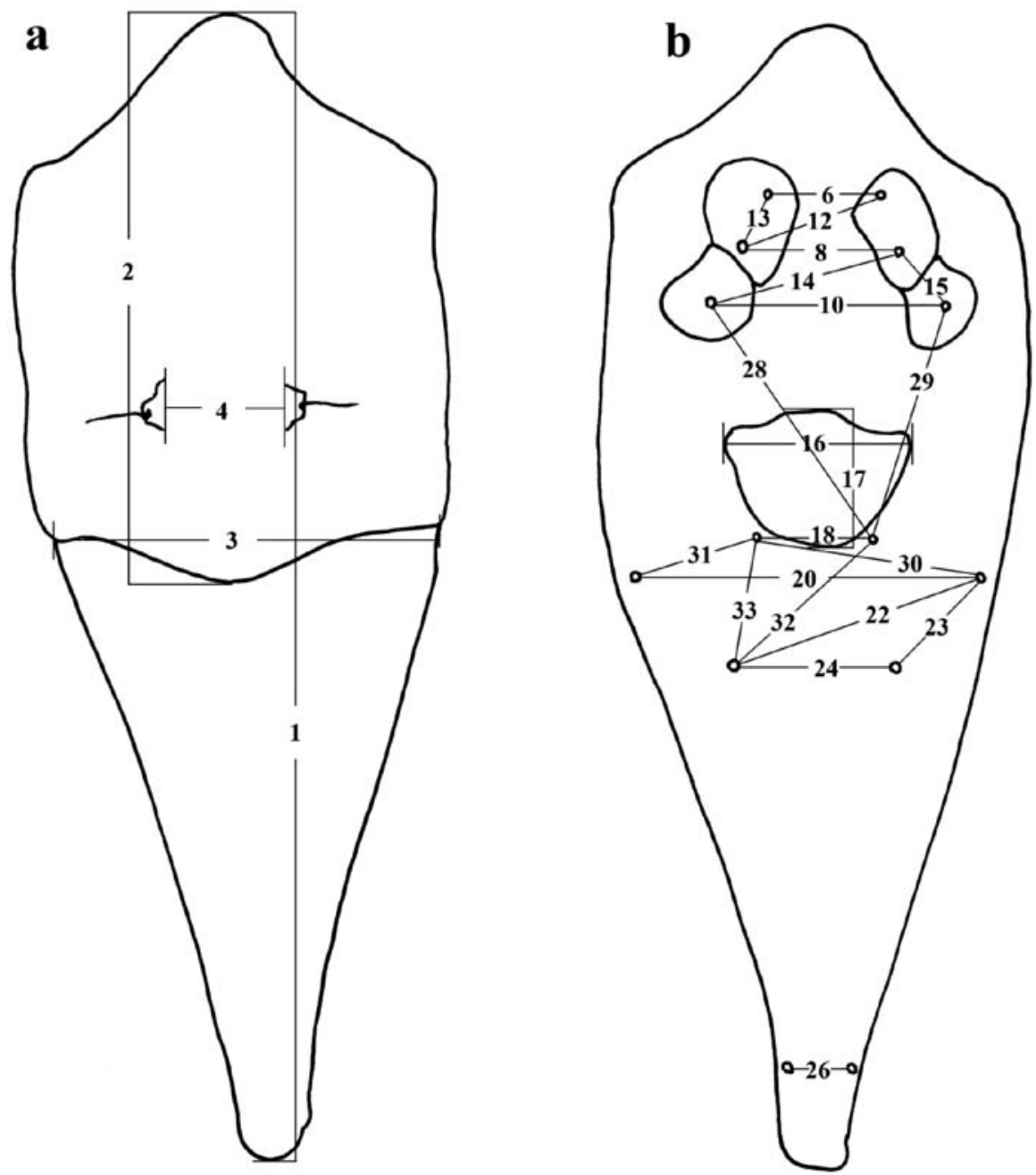

Figure I. Contour drawing of Tumoris sanasaii Huang, 2001 and the measurement of the 33 variables used in this study. The number corresponds to the number of the variable listed in Table 1. a dorsal view b ventral view.

(PCA) was then applied to reduce multicollinearity. Variation among populations in derived orthogonal principal components was firstly identified with MANOVA. Once a significant result was detected, pair-wise MANOVA tests after Bonferroni adjustment ( $\alpha$-level: 0.05 divided by $n$ comparisons) were followed to identify the pair(s) leading to the difference. We also created a canonical centroid plot, which provides a convenient way for simultaneously inspect differences among populations (the canonical centroid plot depicted the $95 \%$ confidence interval for centroid of each population and an overlap of boundary represents no difference in response variables). 
We then applied analysis of variance (ANOVA) to determine which response variable (i.e. PC1, PC2, etc.) accounted for the variation. Lastly, differences in those morphometric measurements with high absolute loadings in selected principal components (those that significantly differed among populations) were tested with ANOVA or $t$-test. For the MANOVA test, normality of response variables (PC values for morphometric measurements) was confirmed with Shapiro-Wilk test, and multivariate outliers were identified with jackknifed Mahalanobis distance. All the procedures were implemented in JMP 8.0 (SAS Institute Inc., Cary, N.C.).

\section{Results and discussion}

\section{Geographical variation}

We applied PCA to reduce the dimensionality in 33 standardize morphometric variables. The three principal axes (PC1-3) were normally distributed within the three locations (Shapiro-Wilk test, $\mathrm{W}$ ranged from 0.92 to 0.97 , all $P>0.05$ ), and there were no outliers in PC values. PC1, PC2, and PC3 varied significantly among the three locations (MANOVA Wilks' $\lambda$ test: $F_{6,60}=6.04, P<0.0001$ ). Canonical centroid plot revealed that morphological characteristics in Yangmingshan (YF) statistically differed from those in Lanyu (LF) and Green Island (GF) (pair-wise MANOVA: $F_{3,11}=13.54$ and $F_{3,20}=14.56$, respectively; both $P<0.001)$, whereas the latter two cannot be distinguished from each other $\left(F_{3,27}=2.59, P>0.05\right)$ (Fig. 2$)$. Further ANOVA showed that these variations were due to the differences in PC1 $\left(F_{2,32}=8.83, P<0.001\right)$ and PC3 $\left(F_{2,32}=8.13, P<0.005\right)$, but cannot be explained by PC2 $\left(F_{2,32}=0.43, P=0.65\right)$. Absolute values of loadings were higher in $\mathrm{Bl}$, Lt-Lt, Lt|Vt1, Vt1-Vt1, Gt $\mid \mathrm{Lt}$, and Gt-Lt for PC1, and higher in $\mathrm{Sw}$ and Ct1-Ct2 for PC3 (Table 2). Among these variables (using original measurements), Bl (YF: 151.7 \pm 3.1 (mean $\pm 1 S D), 147.9-155.2$ (range); LF+GF: 135.3 $\pm 13.2,114.3-$ 178.1; $t$-test, $t=2.44, P<0.05$ ) and $S_{w}(Y F: 61.5 \pm 2.0,58.7-63.3 ; \mathrm{LF}+\mathrm{GF}: 51.7 \pm 5.6$, $39.5-66.8 ; t=3.45, P<0.005)$ in YF were significantly different (all were larger) from those in LF and GF (combined due to similarity in morphology).

\section{Sexual variation}

The three principal axes derived from 33 standardized morphometric variables were normally distributed (W ranged from 0.93 to 0.98 , all $P>0.05$ ), and varied significantly between the males (GM) and the females (GF) in Green Island (MANOVA $F_{3,34}=$ 46.51, $P<0.0001$ ) (Fig. 3). Sexual differences were observed in PC1 ( $t$-test, $t=11.87$, $P<0.001)$, but not in PC2 $(t=-0.51, P=0.62)$ and PC3 $(t=0.14, P=0.89)$. Absolute loadings were higher in $\mathrm{Bl}$, Sl, Ds.l, Ct3-Ct3, Ct1 \Ct2, Gs.w, Gs.l, Gt-Gt, Lt-Lt, Lt Vt1, Lt-Vt1, Vt1-Vt1, Ct3\Gt, Ct3-Gt, Gt lLt, Gt-Lt, and Gt|Vt1 for PC1 (Table 2). 


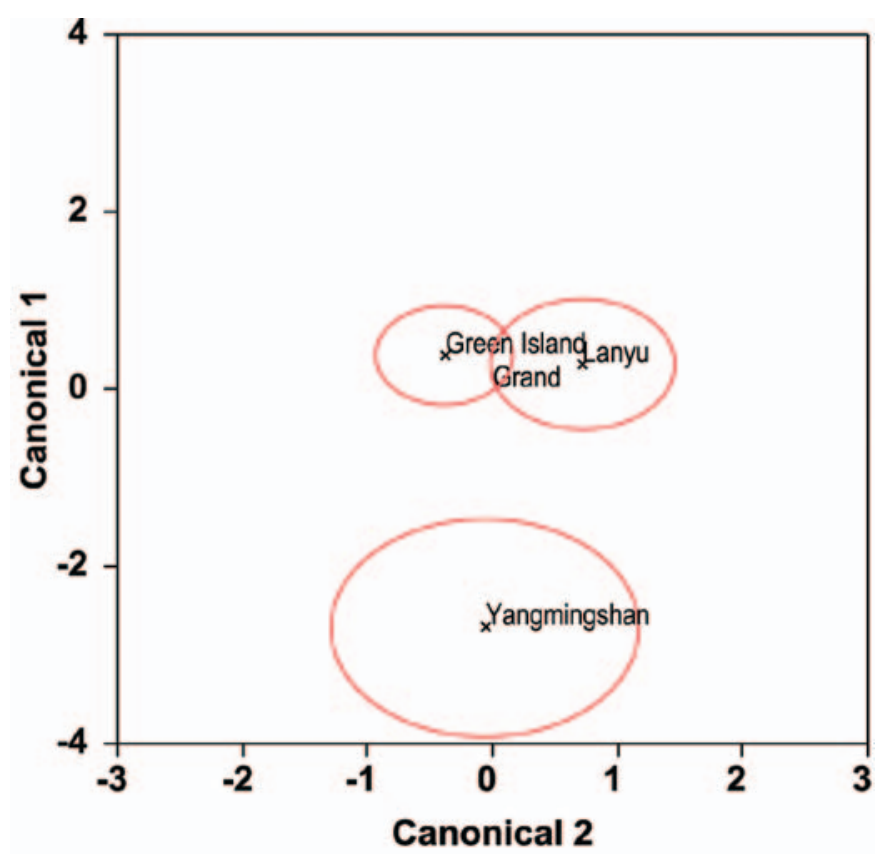

Figure 2. Canonical centroid plot for geographical variation in morphometric characteristics for Yangmingshan (YF), Lanyu (LF) and Green Island (GF).

Sexual variation was observed in all these 17 variables ( $t$-test), with the females significantly larger than the males (Table 3).

\section{Identity of the geographical groups}

The analyses on geographical groups revealed no significant differences between the Lanyu and Green Island populations, indicating that $H$. lanyuensis and T. sanasaii are actually the same. On the other hand, the group from Yangmingshan, previously identified by KWH as Tumoris sanasaii, is distinct. Though sharing similar diagnostic characters with $T$. sanasaii, the Yangmingshan group differs significantly from the true T. sanasaii by morphometry. The former group feeds on a different subspecies of host plant in the temperate northern Taiwan, in contrast to true T. sanasaii living on subtropical or tropical Green Island and Lanyu. At present it is difficult to determine whether it is intra- or inter-specific difference. We would suggest their differentiation being above subspecies level because eriophyid mites have more rapid evolution rate than their host plants. A further study using multidisciplinary approaches would be required to solve the problem.

Owing to the reduced morphological structures and minute size of eriophyids, descriptive diagnosis is usually unsatisfactory in differentiating closely related species. 
Table 2. Loadings in principal components of geographical and sexual variations in morphometric variables of Eriophyoid mites in Taiwan (only PCs that significantly differ among populations were shown).

\begin{tabular}{|c|c|c|c|}
\hline \multirow{2}{*}{$\begin{array}{l}\text { Morphometric } \\
\text { variables }\end{array}$} & \multicolumn{2}{|c|}{ Geographical variation } & \multirow{2}{*}{\begin{tabular}{|r|} 
Sexual variation \\
PC1
\end{tabular}} \\
\hline & PC1 & PC3 & \\
\hline $\mathrm{Bl}$ & -0.85 & 0.27 & 0.60 \\
\hline $\mathrm{Sl}$ & 0.30 & 0.51 & 0.80 \\
\hline Sw & -0.02 & -0.64 & 0.59 \\
\hline Dt-Dt & -0.33 & 0.47 & 0.23 \\
\hline Ds.l & -0.26 & 0.55 & 0.61 \\
\hline $\mathrm{Ct} 1-\mathrm{Ct} 1$ & 0.35 & 0.18 & 0.49 \\
\hline Ct1.1 & -0.01 & 0.19 & 0.27 \\
\hline $\mathrm{Ct} 2-\mathrm{Ct} 2$ & 0.37 & -0.12 & 0.55 \\
\hline Ct2.1 & 0.49 & -0.21 & 0.41 \\
\hline $\mathrm{Ct} 3-\mathrm{Ct} 3$ & 0.23 & -0.19 & 0.66 \\
\hline Ct3.1 & 0.32 & -0.35 & 0.20 \\
\hline $\mathrm{Ct} 1 \backslash \mathrm{Ct} 2$ & 0.54 & 0.27 & 0.60 \\
\hline $\mathrm{Ct} 1-\mathrm{Ct} 2$ & -0.15 & 0.61 & 0.41 \\
\hline $\mathrm{Ct} 2 \backslash \mathrm{Ct} 3$ & 0.40 & -0.12 & 0.58 \\
\hline $\mathrm{Ct} 2-\mathrm{Ct} 3$ & -0.07 & -0.05 & 0.40 \\
\hline Gs.w & 0.57 & 0.03 & 0.90 \\
\hline Gs.l & 0.36 & 0.02 & 0.90 \\
\hline Gt-Gt & -0.05 & -0.10 & 0.74 \\
\hline Gs.1 2 & -0.47 & -0.21 & 0.36 \\
\hline Lt-Lt & 0.66 & 0.48 & 0.83 \\
\hline Lt.l & 0.02 & -0.49 & 0.20 \\
\hline $\mathrm{Lt} \mid \mathrm{Vt} 1$ & 0.71 & 0.18 & 0.85 \\
\hline Lt-Vt1 & 0.33 & -0.19 & 0.65 \\
\hline $\mathrm{Vt} 1-\mathrm{Vt} 1$ & 0.60 & 0.27 & 0.67 \\
\hline Vt1.1 & -0.53 & -0.11 & 0.26 \\
\hline Vt3-Vt3 & 0.04 & 0.15 & 0.14 \\
\hline Vt3.1 & 0.37 & -0.31 & -0.05 \\
\hline $\mathrm{Ct} 3 \backslash \mathrm{Gt}$ & 0.51 & -0.49 & 0.88 \\
\hline Ct3-Gt & 0.39 & -0.40 & 0.72 \\
\hline Gt $\mid \mathrm{Lt}$ & 0.69 & 0.34 & 0.89 \\
\hline Gt-Lt & 0.70 & 0.50 & 0.69 \\
\hline Gt $\mid V t 1$ & 0.60 & -0.17 & 0.85 \\
\hline Gt-Vt1 & 0.40 & -0.24 & 0.37 \\
\hline
\end{tabular}

Molecular identification is also difficult owing to the hardness to isolate a single individual of an identified species from a mite community without making a slide. Morphometric analyses thus provide a reasonable option with balance in effectiveness and efficiency. The present and many previous studies have proved morphometrics a useful tool in eriophyoid classification (Huang et al. 1996; Magud et al. 2007; Skoracka et al. 2002; Navia et al. 2006, 2009; Skoracka 2009a, b). 
Table 3. The 17 characters with significant difference between male and female of Tumoris sanasaii in Green Island.

\begin{tabular}{|c|c|c|c|c|c|}
\hline \multirow{2}{*}{$\begin{array}{c}\text { Morphometric } \\
\text { variables }\end{array}$} & \multicolumn{2}{|c|}{ Male } & \multicolumn{2}{|c|}{ Female } & \multirow{2}{*}{ t-value } \\
\hline & mean $\pm 1 S D$ & range & mean $\pm 1 S D$ & range & \\
\hline $\mathrm{Bl}$ & $126.6 \pm 6.2$ & $114-137$ & $132.7 \pm 9.4$ & $114-159$ & $2.32^{*}$ \\
\hline Sl & $50.0 \pm 2.7$ & $45-54$ & $54.7 \pm 3.1$ & $50-60$ & $5.05^{* * *}$ \\
\hline Ds.l & $6.6 \pm 1.1$ & $4.9-8.7$ & $8.2 \pm 1.8$ & $4.9-12$ & $3.36^{* *}$ \\
\hline $\mathrm{Ct} 3-\mathrm{Ct} 3$ & $16.8 \pm 0.8$ & $14-18$ & $18.5 \pm 1.2$ & $16-20$ & $4.96^{* * *}$ \\
\hline $\mathrm{Ct} 1 \backslash \mathrm{Ct} 2$ & $9.4 \pm 0.6$ & $8.3-11$ & $10.2 \pm 1.0$ & $8.7-13$ & $2.82^{*}$ \\
\hline Gs.w & $14.0 \pm 1.6$ & $11-18$ & $19.0 \pm 1.3$ & $16-21$ & $10.78^{* * *}$ \\
\hline Gs.l & $4.7 \pm 1.5$ & $2.6-7.9$ & $12.3 \pm 1.0$ & $8.9-16$ & $13.36^{* * *}$ \\
\hline $\mathrm{Gt}-\mathrm{Gt}$ & $11.1 \pm 1.4$ & $9-15$ & $14.0 \pm 1.1$ & $12-16$ & $6.95^{* * *}$ \\
\hline $\mathrm{Lt}-\mathrm{Lt}$ & $34.0 \pm 1.4$ & $31-37$ & $37.8 \pm 2.2$ & $33-41$ & $6.39^{* * *}$ \\
\hline $\mathrm{Lt} \mid \mathrm{Vt} 1$ & $29.4 \pm 1.1$ & $26-31$ & $33.7 \pm 2.3$ & $27-38$ & $7.26^{* * *}$ \\
\hline Lt-Vt1 & $18.6 \pm 1.5$ & $16-21$ & $20.8 \pm 2.2$ & $14-23$ & $3.48^{* *}$ \\
\hline Vt1-Vt1 & $15.4 \pm 1.2$ & $12-17$ & $18.7 \pm 2.1$ & $16-24$ & $5.92^{* * *}$ \\
\hline $\mathrm{Ct} 3 \backslash \mathrm{Gt}$ & $21.0 \pm 1.0$ & $19-23$ & $24.8 \pm 1.2$ & $23-28$ & $10.91^{* * *}$ \\
\hline $\mathrm{Ct} 3-\mathrm{Gt}$ & $15.8 \pm 1.3$ & $13-18$ & $18.7 \pm 1.8$ & $17-25$ & $5.68^{* * *}$ \\
\hline $\mathrm{Gt} \backslash \mathrm{Lt}$ & $22.3 \pm 1.1$ & $19-24$ & $25.9 \pm 1.2$ & $24-29$ & $9.31^{* * *}$ \\
\hline Gt-Lt & $10.7 \pm 1.0$ & $9-12$ & $12.3 \pm 1.2$ & $10-14$ & $4.49^{* * *}$ \\
\hline Gt $\mid V t 1$ & $19.5 \pm 1.1$ & $18-21$ & $22.1 \pm 1.3$ & $20-25$ & $6.80^{* * *}$ \\
\hline
\end{tabular}

${ }^{*} P<0.05 ;{ }^{* *} P<0.005 ;{ }^{* * *} P<0.001$

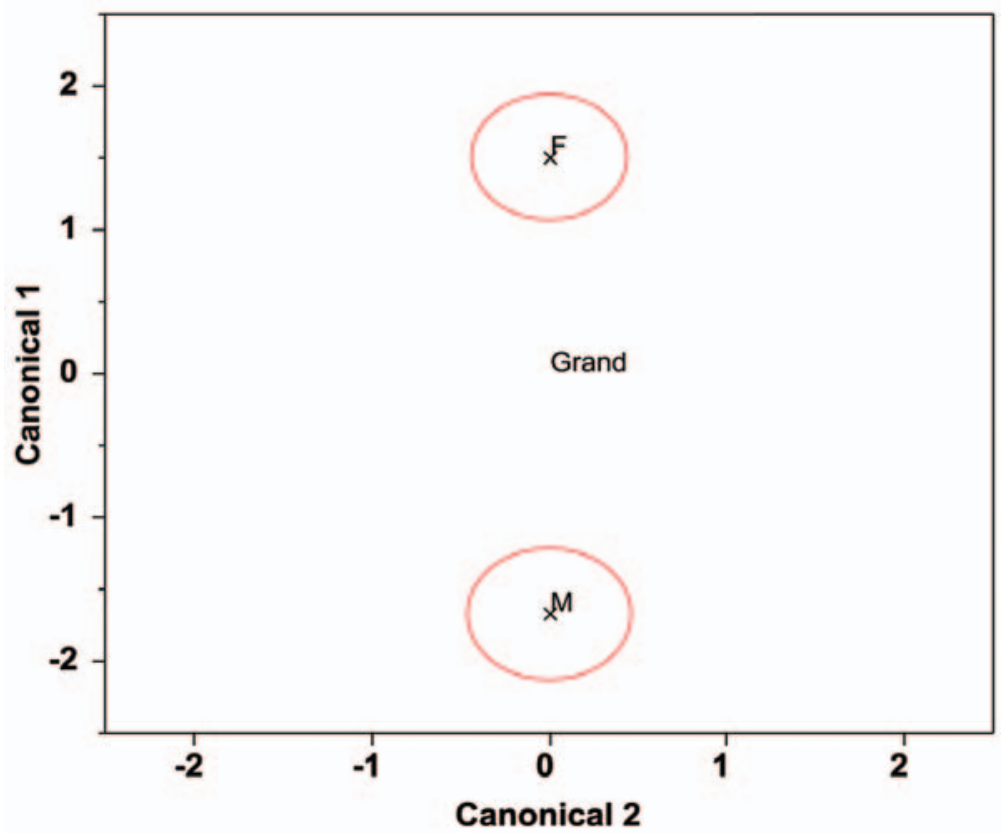

Figure 3. Canonical centroid plot for sexual variation in morphometric characteristics for male (M) and female (F) of Green Island. 


\section{Taxonomy}

\section{Tumoris Huang, 2001: 98}

http://species-id.net/wiki/Tumoris

Plate $1 \mathrm{a}, \mathrm{b}, \mathrm{c}, \mathrm{d}$

Absentia Huang, 2001: 58 (preoc., Absentia Togashi, 1990)

Absentia lanyuensis Huang - type species (=Tumoris sanasaii Huang, syn. n.)

Huangiella Kammerer, 2006: 269 (nom. nov. pro Absentia Huang )(=Tumoris, syn. n.)

Type species: Tumoris sanasaii Huang, by original designation.
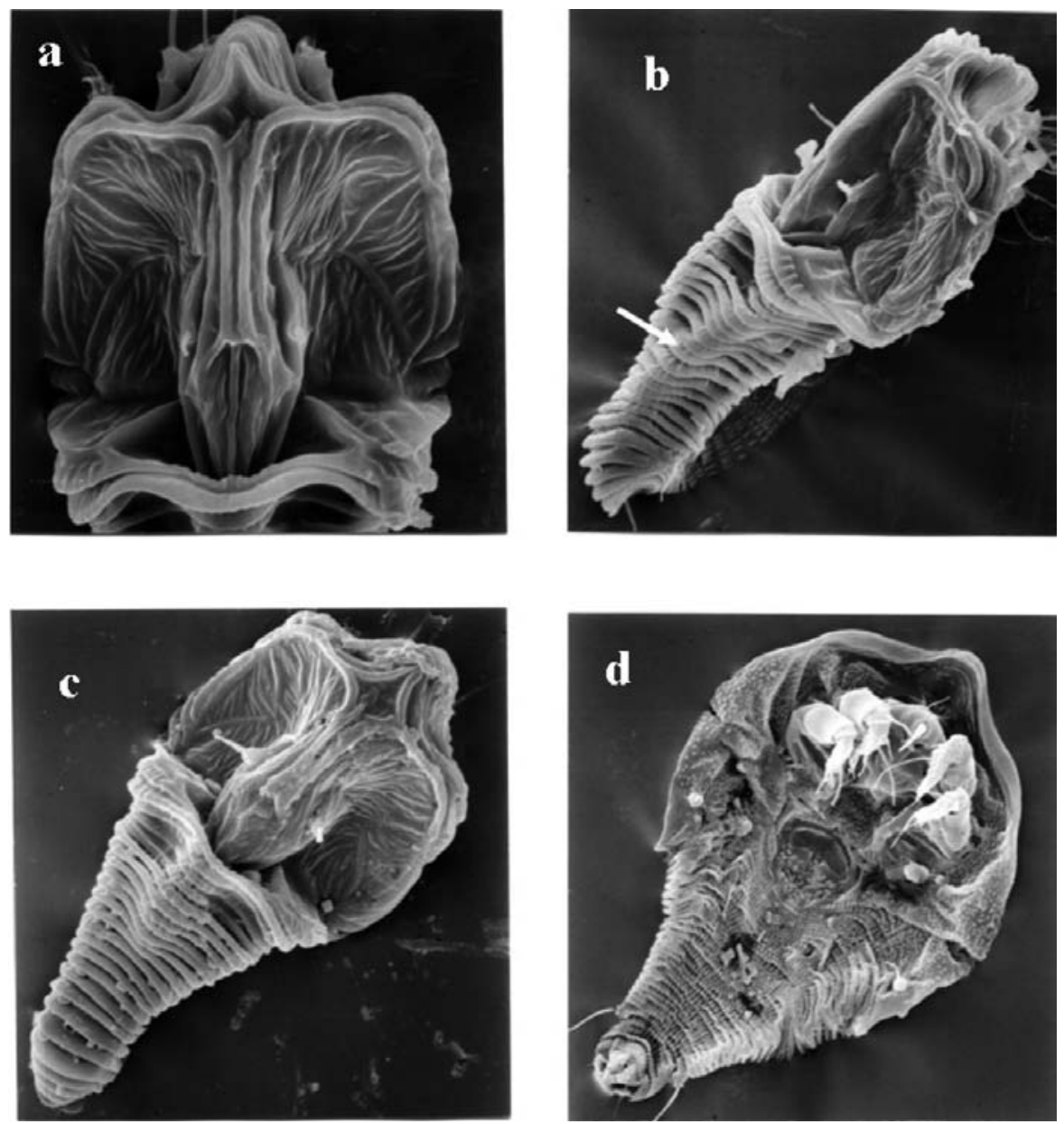

Plate I. SEM micrographs of Tumoris sanasaii Huang, 2001. a prodorsal shield b lateral view, white arrow means submedian ridge $\mathbf{c}$ dorsal view $\mathbf{d}$ ventral view. 
Redefinition of the genus. Body spindle-shape, narrowing abruptly posteriorly; shield pentagonal, lobe present, with bulge between scapular tubercles, scapular tubercles set ahead of rear shield margin, seta directed upward; leg segments normal, coxae with 3 pairs of tubercles and seta, hind genual seta absent; empodium simple; opisthosoma differentiated into broader dorsal annuli and narrower ventral annuli, first dorsal annulus broad, fused forming a broad plate joined to prodorsal shield, dorsum with 3 ridges, median ridge ending before submedian ridges, the second ventral tubercle and setae (e) absent; coverflap with short ridges at base.

Differential diagnosis. This genus is close to Proneotegonotus Mohanasundaram 1983, but differs from the latter by the absence of the second ventral tubercle and setae $(e)$, presence of the first ventral tubercles and setae $(d)$, and a bulge between the dorsal tubercles in prodorsal shield.

Classification. In Huang (2001b) Tumoris was assigned to Tegonotini by the presence of lateral lobes in opisthosoma. After examining more specimens from several localities, we found the lateral lobes previously recognized were actually the submedian ridges on the dorsal opisthosoma (Pl. 1, b). According to the scapular tubercles located ahead of the rear shield, we re-assign this genus to Phyllocoptini.

\section{Acknowledgements}

We wish to thank Mr. C.K. Lin, Drs. C, M. Wang, C.H. Chen, and H.F. Yen (NMNS) for helping us to identify the host plants. Thanks are also due to Miss S.K. Hu for her assistance with the SEM, and to Miss R. Wang and J. Jeng for organizing the data for morphometric analyses. We are grateful to Dr. H.D. Huang (NMNS) for his comment and editorial improvement on this article.

\section{References}

Amrine JW Jr. (1996) Keys to the world genera of the Eriophyoidea. Indira Publishing House, West Bollmfield, Michigan, 186 pp.

Amrine JW Jr., Stasny TA, Flechtmann CHW (2003) Revised keys to world genera of Eriophyoidea (Acari: Prostigmata). Indira Publishing House, West Bloomfield, Michigan, 244 pp. Editorial Committee of the Flora of Taiwan (1998) Flora of Taiwan, 2nd edition, Vol. IV. Dept. of Botany, National Taiwan University, Taipei City.

Huang KW, Huang T, Wang CF (1996) Morphometric analysis between Spinacus pagonis Keifer and its affined species. Zoological Studies 35: 178-187.

Huang KW (2001a) Eriophyoid mites of Taiwan: description of twenty-three species from Lanyu. Bulletin of National Museum of Natural Science 13: 37-63.

Huang KW (2001b) Eriophyoid mites of Taiwan: description of twelve species from Green Island. Bulletin of National Museum of Natural Science 13: 95-109. 
Huang KW (2008) Aceria in Taiwan: five new species and plant abnormalities caused by sixteen species. Zootaxa 1829: 1-30

International Commission on Zoological Nomenclature (1999) International Code of Zoological Nomenclature, 4th edition. International Trust for Zoological Nomenclature, London.

Kammerer CF (2006) Notes on some preoccupied names in Arthropoda. Acta Zootaxonomica Sinica 31: 269-271.

De Lillo E, Amrine, JW Jr. (2003) Catalogue of the Eriophyoidea of the world. Version computer of Filemaker Pro 4.0.

Magud BD, Stanisavljević LŽ, Petanović RU (2007) Morphological variation in different populations of Aceria anthocoptes (Acari: Eriophyoidea) associated with Canada thistle, Cirsium arvense, in Serbia. Experimental and Applied Acarology 42: 173-183. doi:10.1007/ s10493-007-9085-y

Manly BFJ (1990) Multivariate statistical methods: a primer. Chapman and Hall, London. 215pp.

Navia D, Moraes GJ de, Querino RB (2006) Geographic variation in the coconut mite, Aceria guerreronis Keifer: a geometric morphometric analysis. International Journal of Acarology 32: 301-314. doi:10.1080/01647950608684473

Navia D, Moraes GJ de, Querino RB (2009) Geographic pattern of morphological variation of the coconut mite, Aceria guerreronis Keifer (Acari: Eriophyidae), using multivariate morphometry. Brazilian Journal of Biology 69: 773-783. doi:10.1590/S151969842009000400004

Rohlf FJ (2004) NTSYSpc. Numerical taxonomy and multivariate analysis system ver. 2.1. Exeter Software, New York.

Rohlf FJ, Bookstein FL (1987) A comment on shearing as a method for "size correction". Systematic Zoology 36: 356-367. doi:10.2307/2413400

Skoracka A (2009a) Quackgrass- and ryegrass-adapted populations of the cereal rust mite, Abacarus hystrix (Acari: Eriophyidae), differ in their potential for whet, Triticum aestivum, colonization. Bulletin of Entomological Research 99: 33-39. doi:10.1017/S0007485308006093

Skoracka A (2009b) Description of Abacarus lolii n. sp. (Acari: Eriophyoidea: Eriophyidae), a cryptic species within a grass-feeding Abacarus complex. International Journal of Acarology 35: 405-417. doi:10.1080/01647950903292764

Skoracka A, Kuczynski L, Magowski W (2002) Morphological variation in different host populations of Abacarus hystrix (Acari: Prostigmata: Eriophyoidea). Experimental and Applied Acarology 26: 187-193. doi:10.1023/A:1021144729837

Strauss RJ, Bookstein FL (1982) The truss: body form reconstructions in morphometrics. Systematic Zoology 31: 113-135. doi:10.2307/2413032 